\title{
PELINDUNGAN HUKUM TERHADAP SUMBER DAYA GENETIK DAN PENGETAHUAN TRADSIONAL (SDG-PT) PASCA DIUNDANGKANNYA UNDANG-UNDANG NOMOR 13 TAHUN 2016 TENTANG PATEN
}

\author{
${ }^{1}$ Ferianto, ${ }^{2}$ Tommy Hendrix dan ${ }^{3}$ Tuthi' Mazidatur Rohmah \\ 1,2Research Center for Science, Technology and Innovation Policy and Management \\ Indonesian Institute of Sciences, ${ }^{3}$ Business Law, Gadjah Mada University
}

Contact: feriantolipi@gmail.com

Diterima: 05 0kt 2020

Direvisi:

Disetujui:

Hak Cipta: (C) 2018

Halaman: 31-41

\begin{abstract}
The huge potential of genetic resources has made Indonesia one of the goals of bioprospection and even biopiracy from other countries which has actually harmed the Indonesian state both legally and economically. Referring to the importance of managing genetic resources and traditional knowledge, there have been many political results of national law that have been created to regulate the protection and management of genetic resources and traditional knowledge. One of the products of the political law is Law no. 13 of 2016 concerning Patents. Therefore, this study aims to examine the legal protection aspects of genetic resources and traditional knowledge in terms of Law Number 13 of 2016 concerning Patents, opportunities and challenges for Indonesia in utilizing the protection of the SDG to empower an economy based on biodiversity and traditional knowledge. This research is a normative research with qualitative data analysis. Normative research is carried out with a literature study approach consisting of primary and secondary legal materials. The research results show that Law No. 13 Year 2016 regarding Patents have loaded a better legal protection against patentbased genetic resources and traditional knowledge (GR-TK) both preventive and repressive. The opportunity for GR-TK potential is if database can be managed centrally, systematically and completely, it will facilitate utilization and arrangement of benefit sharing access so that benefits felt by Indonesia as country that owns GR-TK are more optimal. The challenge faced is that management of GR-TK database systematically and completely by a special authority has not been established by Government. Arrangements regarding benefit sharing in GR-TK utilization has not made the technical regulations governing them.
\end{abstract}

Keywords: Legal Protection, genetic resources, traditional knowledge, Law Number 13 of 2016 concerning Patents 


\section{PENDAHULUAN}

Indonesia merupakan negara dengan keanekaragaman hayati dan sumber daya genetik yang tinggi (megabiodiversity) setelah Brazil. Tingginya kenanekaragaman hayati plasma nutfah yang dimiliki Indonesia disebabkan bentang alam yang luas dengan penyebaran dan kondisi wilayah geografis bervariasi. (Berlianty, 2017). Kondisi ini akan menjadi sumber kekuatan ekonomi yang kuat jika didukung oleh penguasaan teknologi dalam mengelola dan memanfaatkan potensi Sumber Daya Genetik dan Pengetahuan Tradisional (SDG-PT) yang terkandung di dalam kenakeragaman hayati tersebut. (Mahruzar, 2016). Potensi sumber daya genetik yang besar tersebut telah menjadikan Indonesia menjadi salah satu tujuan bioprospeksi bahkan biopiracy dari negara-negara lain yang justru malah merugikan negara Indonesia baik secara hukum maupun ekonomi.(Nuryanti, 2015).

Sebagai contoh, Kasus Shiseido, sebuah perusahaan kosmetik berasal dari Jepang sejak 1995 diduga melakukan pembajakan hayati dengan mengajukan 51 permohonan paten tanaman obat dan rempah yang telah digunakan oleh Indonesia secara turun temurun. Tahun 2000 Lembaga Swadaya Masyarakat melakukan aksi kampanye luas melalui lokarya publik, konferensi pers, dan lobi intensif. Pada 24 Januari 2002 Shiseido membatalkan permohonan registrasi patennya.(Tami Justicia, 2012). Kasus tersebut memberikan bukti bahwa pentingnya memberikan perlindungan hukum atas invensi yang memanfaatkan SDG-PT. Merujuk pentingnya pengelolaan atas SDG-PT, telah banyak hasil politik hukum nasional yang dilahirkan untuk mengatur pelindungan dan pengelolaan SDG-PT tersebut (Nuryanti, 2015). Salah satu produk hasil politik hukum tersebut adalah UU No. 13 Tahun 2016 tentang Paten.

Undang-undang tersebut mengatur cakupan pelindungan hukum yang diharapkan lebih baik di bidang SDG khususnya mengenai kewajiban mencantumkan asal sumber SDG dan Pengetahuan Tradisional serta kewajiban untuk pembagian keuntungan (benefit sharing) yang adil atas pemanfaatan SDG dan Pengetahuan Tradisional tersebut. Oleh karena itu, penelitian ini bertujuan untuk mengkaji lebih dalam aspek pelindungan hukum terhadap SDG-PT ditinjau dari UU No. 13 Tahun 2016 tentang Paten, peluang dan tantangan Indonesia dalam memanfaatkan pelindungan SDG-PT untuk memerikan manfaat ekonomi.

\section{METODE PENELITIAN}

Penelitian ini berjenis penelitian hukum. Maria (2014) menjelaskan bahwa jenis penelitian normatif merupakan penelitian berdasatkan peraturan tertulis atau bahan-bahan hukum yang lain sehingga penelitian ini dilakukan terhadap data yang bersifat sekunder yang ada di perpustakaan. Bahan hukum primer yaitu bahan hukum yang bersifat mengikat dalam penelitian ini terdiri atas: TRIP'S Agreement, Convention on Biological Diversity (CBD), UU No.13 Tahun 2016 tentang Paten, UU No.14 Tahun 2001 tentang Paten, Peraturan Pemerintah yang berkaitan dengan paten, dan Protokol Nagoya. Bahan hukum sekunder yaitu bahan-bahan yang 
memberikan petunjuk dan kejelasan terhadap bahan hukum primer yang meliputi RUU Paten, buku/literatur, jurnal, prosiding, makalah, karya tulis lain yang relevan dalam mendukung topik penelitian ini. Kemudian data yang terkumpul dilakukan analisis secara kualitatif dan data disajikan bersifat deskriptif. (Maria, 2014).

\section{HASIL DAN PEMBAHASAN}

Pelindungan Hukum SDG Pasca Diundangkannya UU No.13 Tahun 2016 Tentang Paten

Penelitian ini memberikan batasan pelindungan hukum sebagai suatu upaya yang dilakukan di bidang hukum dengan maksud dan tujuan memberikan jaminan pelindungan hukum paten terhadap objek pelindungan yaitu invensi yang menggunakan SDG -PT demi mewujudkan kepastian hukum baik pelindungan secara preventif maupun represif. Pelindungan hukum terbagi menjadi dua bagian yaitu perlindungan preventif, merupakan pelindungan yang diberikan oleh pemerintah dengan tujuan untuk mencegah sebelum terjadinya pelanggaran. Hal ini terdapat dalam peraturan perundang-undangan dengan maksud untuk mencegah suatu pelanggaran serta memberikan ramburambu atau batasan-batasan dalam melakukan suatu kewajiban. Pelindungan hukum represif merupakan pelindungan akhir berupa sanksi seperti denda, penjara, dan hukuman tambahan yang diberikan apabila sudah terjadi sengketa atau telah dilakukan suatu pelanggaran.(Hadjon, 1987).

Marzuki (2008) menjelaskan bahwa pelindungan hukum dalam hal ini akan bermuara pada tiga tujuan hukum yaitu kepastian, kemanfaatan dan keadilan. Kepastian hukum artinya dengan dilindunginya paten akan sangat jelas invensi seperti apa yang dapat dilindungi paten dan siapa pemiliknya. Kemanfaatan, mengandung arti bahwa dengan invensi dilindungi paten maka akan ada manfaat yang akan diperoleh terutama bagi pihak yang melakukan pelindungan itu sendiri, semisal; dapat memberikan lisensi bagi pihak yang memegang hak atas paten dengan manfaat berupa pembayaran royalti (royalty payment). Keadilan dalah dapat memberikan kesejahteraan bagi pihak pemegang khususnya dalam wujud peningkatan pendapatan, bagi masyarakat dapat memperoleh akses teknologi untuk memenuhi kebutuhan hidup, serta pada akhirnya memberikan dampak ekonomi kepada negara.

Perlindungan hukum preventif tersebut meliputi diratifikasinya berbagai konvensi internasional tentang paten yang menggunakan SDG. Diratifikasinya konvensi internasional tersebut mengharuskan Indonesia tunduk pada aturan-aturan didalamnya. Konvensi atau perjanjianperjanjian terkait paten untuk invensi yang menggunakan sumber daya genetik meliputi. (Citrawinda, 2016):

1. Agreement on Trade Related Aspects of Intellectual Property Rights (Persetujuan TRIPs)

Perjanjian ini telah diratifikasi Indonesia melalui UU No. 7 Tahun 1994 tentang Pengesahan Agreement Establishing The World Trade Organization. TRIPs ini merupakan bagian dari salah satu persetujuan di 
bawah WTO.

SDG merupakan sesuatu yang murni berasal dari alam, namun sesuatu yang natural dari alam tersebut bisa diberikan perlindungan paten apabila dapat dimanfaatkan dan mempunyai langkah inventif. Hal ini sebagaimana dituangkan dalam TRIPs Pasal 27 ayat (1) yang menyatakan bahwa paten diberikan untuk setiap invensi, baik produk maupun proses dalam semua bidang teknologi sepanjang invensi tersebut baru, mempunyai langkah inventif dan diterapkan dalam industri (Berlianty, 2017).

Selanjutnya, dalam TRIPs Pasal 27 ayat (3) menjelaskan bahwa mikroorganisme baik yang telah ada di alam atau hasil rekayasa genetika merupakan subyek matter yang patentable. Kedua ketentuan ini menjadi awal pijakan bagi perlindungan paten berbasis SDG selanjutnya disebabkan karena (Berlianty, 2017):

a. Perjanjian TRIPs memungkinkan adanya pemberian perlindungan paten yang memanfaatkan SDG (paten untuk material genetika dan produk turunannya dan varietas tanaman tertentu dengan sistem sui generis), walaupun dalam ketentuan ini perjanjian TRIPs tidak memberikan pengaturan bagaimana hak paten atau varietas tanaman diperoleh, apakah konsisten atau tidak dengan hak negara asal SDG tersebut, ada atau tidak keseimbangan antara negara berkembang sebagai pemilik SDG dan negara maju sebagai pelaku pengembangannya dengan teknologinya.

b. Perjanjian TRIPs hanya menyediakan perlindungan material genetika dan produk turunannya tanpa memberikan ketentuan prior informed consent dan benefit sharing.

Perjanjian TRIPs ini pada dasarnya tidak memfasilitasi perlindungan atas SDG (bisa dikatakan perlindungannya sangat minim), pengaturannya hanya menempatkan pemilik SDG menjadi negara yang dapat memperoleh manfaat dan keuntungan ketika SDG mereka dipatenkan oleh pihak manapun terutama negara maju (Berlianty, 2017).

2. United Nations Convention on Biological Diversity (CBD)

CBD ini diratifikasi oleh Indonesia melalui UU No. 5 Tahun 1994 tentang Pengesahan United Nations Convention on Biological Diversity (CBD). Konvensi Keanekaragaman Hayati ini merupakan sebuah perjanjian antar negara untuk melestarikan sumber daya hayati yang berlaku mengikat kepada para pihak yang menandatanginya. Konvensi Keanekaragaman Hayati tercetus karena kekhawatiran terhadap laju pembangunan yang di sisi lain menyebabkan kepunahan berbagai spesies kehidupan. Untuk menghentikan kerusakan yang semakin parah diperlukan sebuah kesepakatan yang mengatur penggunaan sumber daya hayati. Konvensi ini memiliki tiga tujuan utama yaitu, melestarikan keanekaragaman hayati, memanfaatkan secara berkelanjutan keanekaragaman hayati, dan memastikan pembagian keuntungan yang adil dari hasil 
pemanfaatan sumber-sumber genetic (UU No. 5 Tahun 1994 tentang Pengesahan United Nations Convention on Biological Diversity (CBD)).

Tahap konvensi ini SDG sudah mulai diperhatikan secara detail, pada ketentuan Pasal 3 CBD menegaskan bahwa setiap negara memiliki kedaulatan untuk mengeksploitasi sumber daya alamnya sesuai dengan kebijakan pembangunan dan lingkungannya. Ketentuan ini memberikan hak kedaulatan yang tinggi bagi negara berkembang yang memiliki SDG untuk mengatur dan mengontrol segala akses yang berkaitan dengan pemanfaatan SDG. Selain itu dipertegas kembali pada Pasal 15 ayat (1) CBD "Recognizing the sovereign rights of States over their natural resources, the authority to determine access to genetic resources rests with the national governments and is subject to national legislation".

Ketentuan-ketentuan dalam CBD ini tentunya selaras dengan konstitusi Undang-Undang Dasar Negara Republik Indonesia (UUD NRI Tahun 1945) Pasal 33 ayat (3) yang mengatakan bumi, air dan kekayaan alam yang terkandung di dalamnya dikuasai oleh negara dan dipergunakan untuk sebesar-besarnya kemakmuran rakyat.

CBD merupakan salah satunya perjanjian internasional yang secara khusus mengakui peran pengetahuan tradisional, inovasi, dan praktik-praktik dalam pelestarian keanekaragaman hayati dan pembangunan berkelanjutan sekaligus menjamin perlindungannya baik melalui HKI maupun bentuk lainnya.

3. The Budapest Treaty on the International Recognition the Deposit of Microorganisma for the Purposes of Patent Procedure.

Perjanjian ini memungkinkan deposit mikroorganisme di otoritas penyimpanan internasional untuk diakui untuk keperluan prosedur paten. Biasanya, untuk memenuhi persyaratan hukum kecukupan pengungkapan, aplikasi paten dan paten harus mengungkapkan dalam uraian mereka subjek penelitian dengan cara yang cukup jelas dan lengkap serta menyebutkan asal SDG dan tempat penyimpanannya. Penemuan yang melibatkan mikroorganisme, deposit bahan biologis harus dibuat di lembaga yang diakui. Perjanjian Budapest memastikan bahwa seorang pemohon, yaitu orang yang mengajukan paten, tidak perlu menyimpan bahan biologis di semua negara di mana ia ingin mendapatkan paten. Pemohon hanya perlu menyimpan bahan biologis di satu institusi yang diakui, dan deposit ini akan diakui di semua negara pihak pada Perjanjian Budapest (Pasal 15 The Budapest Treaty on the International Recognition of the Deposit of Microorganisms for the Purposes of Patent Procedure).

4. Protokol Nagoya

Indonesia meratifikasi Protokol Nagoya dengan diundangkannya UU No. 11 Tahun 2013 tentang Pengesahan Nagoya Protocol on Access to Genetic Resources and The fair and Equitable Sharing of Benefits arising from their Utilization to The Convention On Biological Diversity (Protokol Nagoya 
tentang Akses pada Sumber Daya Genetik dan Pembagian Keuntungan yang adil dan seimbang yang timbul dari pemanfaatannya atas Konvensi Keanekaragaman Hayati).

Protokol Nagoya adalah perjanjian internasional yang mengatur tentang akses terhadap SDG dan pembagian keuntungan yang adil dan seimbang antara pemanfaat dan penyedia SDG. Protokol ini merupakan tonggak perjanjian dalam tata kelola internasional mengenai keanekaragaman hayati dan relevan dalam pemanfaatan dan pertukaran SDG, sebagimana diatur dalam Pasal 6.

Nagoya Protocol on Access to Genetic Resources and the Fair and Equitable Sharing of Benefits Arising from their Utilization to the Convention on Biological Diversity, Article 6:

(1) In the exercise of sovereign rights over natural resources, and subject to domestic access and benefitsharing legislation or regulatory requirements, access to genetic resources for their utilization shall be subject to the prior informed consent of the Party providing such resources that is the country of origin of such resources or a Party that has acquired the genetic resources in accordance with the Convention, unless otherwise determined by that Party.

(2) In accordance with domestic law, each Party shall take measures, as appropriate, with the aim of ensuring that the prior informed consent or approval and involvement of indigenous and local communities is obtained for access to genetic resources where they have the established right to grant access to such resources.

Pembagian yang adil dan merata dari keuntungan yang dihasilkan dari pemanfaatan SDG merupakan poin ketiga dari tujuan CBD. Tujuan yang pertama adalah tujuan konservasi keanekaragaman hayati. Oleh karena itu protokol Nagoya dibuat berdasarkan prinsip fundamental dari access and benefit sharing. Prinsip tersebut meliputi:

a. Bahwa pengguna potensial dari SDG memperoleh persetujuan atas dasar informasi awal (PADIA) atau prior informed consent (PIC) dari negara dimana SDG berada sebelum mengakses sumber daya tersebut;

b. Menegoisasikan serta menyetujui syarat dan kondisi dari akses dan pemanfaatan dari SDG tersebut melalui pembuatan kesepakatan bersama (mutually agreed terms). Kesepakatan ini juga termasuk pembagian keuntungan.

Protokol Nagoya ini juga sebagai wujud realisasi amanat Pasal 15 CBD:

"Each Contracting Party shall endeavour to create renditions to facilitate access to genetic resources for environmentally sound uses by other Contracting Parties and not to impose restrictions that run counter to the objectives of this Convention"

serta mencegah pencurian SDG dan pengetahuan tradisional sebagaimana Pasal 8 huruf j CBD:

"Each Contracting Party shall endeavour to create renditions to facilitate access to genetic resources for environmentally 
sound uses by other Contracting Parties and not to impose restrictions that run counter to the objectives of this Convention"

Pengetahuan tradisional yang berkaitan dengan SDG merupakan bagian yang tidak terpisahkan dari SDG dan secara berkelanjutan diwariskan oleh nenek moyang masyarakat hukum adat dan komunitas lokal kepada generasi berikutnya. Protokol Nagoya mengatur akses terhadap SDG dan pembagian keuntungan yang adil dan seimbang antara pemanfaat dan penyedia SDG berdasarkan persetujuan atas dasar informasi awal dan kesepakatan bersama serta bertujuan untuk mencegah pencurian keanekaragaman hayati (biopiracy). Ketentuan tersebut sejalan dengan Pasal 29 TRIPs yang mengatur mengenai kewajiban pemohon paten untuk mengungkapkan invensinya.

Ketentuan Pasal 29 TRIPs mensyaratkan bahwa permohonan paten harus mengungkapkan secara lengkap dan jelas invensinya, karenanya dipertimbangkan bahwa pengungkapan asal SDG dan/atau pengetahuan tradisional dalam permohonan paten diperlukan untuk memenuhi persyaratan ini. Ketentuan ini tidak termuat sama sekali dalam UU No. 14 Tahun 2001 tentang Paten meskipun pada saat UU ini disahkan Indonesia telah meratifikasi Convention on Biological Diversity (CBD) sehingga undang-undang ini kurang memberikan perlindungan hukum terhadap invensi yang melibatkan SDG.

Selain itu, Pasal 15 The Budaphest Treaty juga mensyaratkan adanya pencantuman tempat deposit bank kode mikroorganisme disimpan juga harus disebutkan secara jelas. Ketentuan ini juga belum diatur secara eksplisit maupun implisit dalam UU No.14 Tahun 2001 tentang Paten (UU Paten lama), namun UU No.13 Tahun 2016 tentang Paten telah memberikan perbaikan dan kepastian pelindungan atas sumberdaya genetik Indonesia jika invensi berkaitan dengan dan/atau berasal dari sumber daya genetik dan/atau pengetahuan tradisional, harus disebutkan dengan jelas dan benar asal sumber daya genetik dan/atau pengetahuan tradisional tersebut dalam diskripsi sebagaimana disebutkan dalam Pasal 26 ayat (1) UU No.13 Tahun 2016 tentang Paten.

Berkaitan dengan Protokol Nagoya yang mengatur pembagian keuntungan yang adil dan seimbang antara pemanfaat dan penyedia SDG berdasarkan persetujuan awal. UU No.13 Tahun 2016 tentang Paten juga memberikan pengaturan mengenai hal ini sebagaimana dijelaskan dalam Pasal 26 ayat (3), pembagian hasil dan/atau akses pemanfaatan sumber daya genetik dan/atau pengetahuan tradisional dilaksanakan sesuai dengan peraturan perundangundangan dan perjanjian internasional di bidang sumber daya genetik dan pengetahuan tradisional. Selain itu, pada penyebutan asal dari SDG dalam deskripsi supaya SDG dan/atau pengetahuan tradisional diakui negara lain serta mendukung Access Benefit Sharing (ABS) (Penjelasan Pasal 26 ayat (1) UndangUndang Nomor 13 Tahun 2016 tentang Paten.). Uraian tersebut menggambarkan bahwa undang-undang paten yang lama ini belum memiliki perlindungan hukum yang maksimal. 
Negara melalui UU No.13 Tahun 2016 tentang Paten berusaha untuk meningkatkan pelindungan kepada inventor dan masyarakat bagi kepentingan nasional agar dapat mendorong paten pada SDG seperti mikroorganisme dan pengetahuan tradisional, misalanya jamu, herbal dan kuliner. Apabila ada kerja sama dengan asing dalam dua hal tersebut, maka mereka harus turut mencantumkan sumber daya alam dari Indonesia. Dengan begitu, akan ada pembagian hasil antara ahli olah teknologi dari asing dengan petani Indonesia. Dapat disimpulkan bahwa undang-undang ini tetap berpihak nasional tetapi tidak melanggar prinsip internasional, namun maksud yang sudah baik dari undang-undang ini yang tertkait dengan akses SDG dan benefit sharing belum dibentuk aturan teknis pelaksanaannya sehingga masih memberikan kekosongan hukum pelaksaanaan dari pasal tersebut.

Berkaitan dengan penyimpanan jasad renik secara nasional sebagaimana diamanatkan dalam Pasal 26 ayat (2) juga belum terintegrasi satu pintu sehingga menimbulkan ketidakpastian bagi peneliti berkaitan dengan akses jasad renik ini. Inisiasi telah dilakukan oleh LIPI dengan membangun Indonesia Culture Collection namun secara kelembagaan nasional belum diresmikan sebagai satu-satunya tempat dan akses deposit mikroorganisme.

Selain perlindungan preventif yang diberikan oleh negara, perlindungan represif yang diharapkan memberikan efek jera bagi para pelaku yang menyimpang peraturan. Dalam hal ini Pasal 137 UU No.13 Tahun 2016 mengatur mengenai penghapusan paten, paten dapat dihapuskan jika menggunakan sumber daya genetik dan/atau pengetahuan tradisional tanpa menyebutkan sumbernya. Hal ini menjamin pemilik SDG-PT untuk diakui haknya baik secara moral dan ekonomi atas pemanfaatan paten berbasis SDG-PT. Dengan ketetuan baru ini diharapkan kasus serupa tidak akan terulang kembali dan akan memberikan pelindungan yang lebih baik kepada semua pihak baik pemegang paten maupun pemilik sumber daya untuk menghasilkan paten tersebut. Hal lebih penting lagi yang perlu dilakukan pemerintah adalah memastikan penataan database yang sistematis dan komprehensif terhadap SDG-PT karena akan menjadi basis data acuan dalam memperkuat efektifnya Pasal 26 serta menjadi dokumen pembanding atas kebaruan suatu paten (Utomo, 2010).

\section{Peluang dan Tantangan SDG bagi Indonesia}

Pendokumentasian database atas SDGPT adalah hal yang sangat penting untuk dilaksanakan. Hal ini akan memastikan bahwa kekayaan Indonesia dapat dilindungi secara optimal, apabila ada aspek komersialisasi paten yang memanfaatkan SDG-PT, maka negara dapat mengklaim untuk memperoleh manfaat secara ekonomi sehingga diharapkan dapat memberdayakan ekonomi daerah asal SDG-PT tersebut. Basis data ini akan menjadi suatu bukti bahwa sumber daya genetik tersebut merupakan sumber daya genetik Indonesia dan pihak lain yang mengklaim sumber daya genetiknya disebut sebagai tindakan misappropriation.

Sudaryat (2020) menjelaskan, basis data (database) merupakan kumpulan data 
yang disimpan secara sistematis di dalam komputer yang dapat diolah atau dimanipulasi menggunakan perangkat lunak (program aplikasi) untuk menghasilkan informasi. Pendefinisian basis data meliputi spesifikasi beruba tipe data, struktur data dan juga batasanbatasan pada data yang kemudian disimpan. Basis data merupakan aspek yang sangat penting guna menghindari duplikasi data, mengorganisasi data dan menghindari hubungan antar data yang tidak jelas dan juga update yang sulit.

Apabila database ini dilakukan tentunya menjadi daya dukung utama dalam mendukung penegakan hukum di Indonesia atas tindakan bioprospecting SDG-PT yang dilakukan oknum-oknum yang tidak bertanggungjawab sebagaimana amanat dari Konvensi Keanekaragaman Hayati dan Protokol Nagoya. Daya dukung tersebut bisa dilihat dari pengakuan adanya bukti elektronik dalam proses penegakan hukum di Indonesia. Legalitas alat bukti elektronik dalam Pasal 5 ayat (1) dan (2) Jo. Pasal 44 huruf b sebagaimana telah diubah oleh UU No. 19 Tahun 2016 tentang perubahan atas UU No.11 Tahun 2008 tentang Informasi dan Transaksi Elektronik, diatur dalam BAB III tentang Informasi, Dokumen, dan Tanda Tangan Elektronik, Informasi Elektronik dan/atau Dokumen Elektronik dan/atau hasil cetaknya sebagaimana dimaksud pada ayat (1) merupakan perluasan dari alat bukti yang sah sesuai dengan Hukum Acara yang berlaku di Indonesia.

Selanjutnya, berkaitan dengan Lembaga yang memiliki otoritas mengelola SDG-PT, Indonesia masih menghadapi tantangan yang cukup besar karena SDG-PT masih dikelola secara tersebar dan terpisah oleh masyarakat pemilik SDG-PT, berbagai lembaga penelitian dan pengembangan baik pada kementerian dan Lembaga yang membidangi SDG seperti Kehutanan, Lingkungan Hidup, Kesehatan, Pertanian, Kelautana dan Perikanan, LIPI dan Lembaga lainnya. Penyatuan pengelolaan SDG-PT ke dalam satu instansi terpusat tentu masih relatif sulit (Nuryanti, 2015).

Peluang yang dapat dimanfaatkan dari tantangan mengenai keberadaan instansi atau otoritas yang mengelola SDG-PT secara terpusat adalah idealnya Pemerintah membuat satu otoritas tunggal yang akan mengidentifikasi, mengumpulkan dan mengelola SDG-PT yang masih tersebar di berbagai instansi pemerintah saat ini. Rencana ini jika dikomunikasikan dan dikoordinasikan antar kementerian/Lembaga secara baik serta mengesampingkan ego sectoral maka pembentukan otoritas secara terpusat dan tunggal ini dapat terwujud (Nuryanti, 2015).

Instansi/otoritas ini yang akan menyediakan database secara sistematis dan lengkap terkait SDG-PT di Indonesia yang akan memudahkan berbagai pihak yang akan memanfaatkan potensi SDG-PT tersebut. Penyajian database secara terpusat akan mempermudah pemanfaatan maupun pengaturan access benefit sharing sehingga manfaat yang dirasakan Indonesia sebagai negara SDGPT lebih optimal. Namun, berkaitan dengan pengaturan benefit sharing ini, masih menjadi tantangan pemerintah 
karena sampai saat ini peraturan teknis yang mengatur benefit sharing belum dibuat sehingga ketentuan umum yang sudah ada di dalam UUP baru belum dapat dilaksanakan secara optimal.

\section{KESIMPULAN}

Undang-Undang No. 13 Tahun 2016 tentang Paten telah memuat pelindungan hukum yang lebih baik terhadap paten yang berbasis sumber daya genetik dan pegetahuan tradisional baik secara preventif maupun represif. Peluang atas potensi SDG-PT yaitu jika dapat database dapat dikelola secara terpusat, sistematis dan lengkap maka akan mempermudah pemanfaatan maupun pengaturan access benefit sharing sehingga manfaat yang dirasakan Indonesia sebagai negara pemilik sumber SDG-PT dengan lebih optimal. Tantangan yang dihadapi yaitu pengelolaan database SDG-PT secara sistematis dan lengkap oleh satu otoritas khusus belum dibentuk oleh Pemerintah. Pengaturan mengenai benefit sharing atas pemanfaatan SDG dan pengetahuan tradisional belum dibentuk dan dibuat peraturan teknis yang mengaturnya.

\section{DAFTAR PUSTAKA}

\section{Buku dan/atau Artikel Ilmiah lain}

Berlianty, Teng. (2017). Formulasi Pengaturan Disclosure Requirements Sumber Daya Genetik sebagai Hak Paten. Jurnal Kertha Patrika. Vol. 39, No.2, Agustus 2017.

Citrawinda, Cita. (2016). Permohonan Paten Terkait Jasad Renik Ditinjau dari Peraturan Perundang-Undangan, Media HKI, Vol. XIII/Edisi III.
Hadjon. (1987). Pelindungan Bagi Rakyat di Indonesia. Surabaya: PT.Bina Ilmu.

Justisia, Tami. (2012). Perlindungan Sumber Daya Genetika. Skripsi. FH UI.

Mahruzar. Undang-Undang Nomor 13 Tahun 2016 Tentang Paten : Pandangan dan Ulasan Substansi. Media HKI, Vol. XIII/Edisi VI Tahun 2016.

Marzuki. (2008). Pengantar Ilmu Hukum. Jakarta: Kencana.

Nuryanti, A. (2015). Sumber Daya Genetik dan Pengetahuan Tradisional Terkait Sumber Daya Genetik Untuk Kemakmuran. Jurnal MMH, Vol. 44 No 4, Oktober 2015.

Sudaryat. Perlindungan Hukum Sumber Daya Genetik Indonesia dan Optimalisasi Tekhnologi Indornasi, Jurnal Bina Hukum Lingkungan, Vol. 4 No. 2 April 2020. doi: http://dx.doi.org/10.24970/bhl.v4i2.98

Sumardjono, Maria. (2014). Metodologi Penelitian Ilmu Hukum. Yogyakarta: Fakultas Hukum.

Utomo, Tomi Suryo. (2010). Hak kekayaan Intelektual di Era global, Yogyakarta: Graha Ilmu.

\section{Peraturan Terkait}

Undang-Undang Dasar Negara Republik Indonesia Tahun 1945 (UUD NRI 1945).

Undang-Undang Nomor 5 Tahun 1994 Tentang Pengesahan United Nations Convention on Biological Diversity (CBD), 
Tambahan Lembaran Negara Republik Indonesia Nomor 3556.

Undang-Undang Nomor 14 Tahun 2001 Tentang Paten, Tambahan Lembaran Negara Republik Indonesia Nomor 4130.

Undang-Undang Republik Indonesia Nomor 11 Tahun 2013 tentang Pengesahan Akses pada Sumber Daya Genetik dan Pembagian Keuntungan yang Adil dan Seimbang yang Timbul dari Pemanfaatannya atas Konvensi Keanekaragaman Hayati, Tambahan Lembaran Negara Republik Indonesia Nomor 5412.

Undang-Undang Nomor 13 Tahun 2016 Tentang Paten Tentang Paten, Tambahan Lembaran Negara Republik Indonesia Nomor 5922.

Undang-Undang Nomor 19 Tahun 2016 tentang Perubahan atas UU No.11 Tahun 2008 tentang Informasi dan Transaksi Elektronik, Tambahan Lembaran Negara Republik Indonesia Nomor 251.

Peraturan Pemerintah No. 28 Tahun 2019 Mengenai Perubahan Jenis dan Tarif Layanan Kekayaan Intelektual.

Tim Perumus Naskah Akademik RUU Paten. 2015. Naskah Akademik RUU Paten. Jakarta : BPHN Kemenkumham.

Agreement on TRIPs, Section 5, dari Article 27 Patentable Subject Matter..

Nagoya Protocol on Access to Genetic Resources and the Fair and Equitable Sharing of Benefits Arising from their Utilization to the Convention on Biological Diversity, Article 6.
The Budapest Treaty on the International Recognition of the Deposit of Microorganisms for the Purposes of Patent Procedure.

World Intellectual Property Organization, Agreement between the World Intellectual Property Organization and the WTO (1995) and TRIP's Agreement (1994), (Geneva: WIPO, 1997). 